\title{
Del Nido vs St Thomas II Cardioplegia in Adult cardiac surgery: A prospective randomized trial of short-term outcomes
}

\author{
Aravind Kalyanasundaram ${ }^{1}$, Sreevathsa Prasad ${ }^{1}$, Ram Sankar Padmanabhan ${ }^{1}$, \\ Hemachandran Munusamy ${ }^{1}$, Bathal SaiChandran ${ }^{1}$, and Durgaprasad Rath ${ }^{1}$ \\ ${ }^{1}$ Jawaharlal Institute of Postgraduate Medical Education
}

September 29, 2021

\begin{abstract}
Aim/Objective: To assess short term clinical outcomes based on peri-operative troponin T levels (before start of surgery, 2 hours and 12 hours after coming of $\mathrm{CPB}$ ) of adult patients undergoing cardiac surgery using the del Nido cardioplegia technique compared with st thomas conventional blood cardioplegia Material and method: This was a prospective randomized study with a sample size of 100, which included patients with valvular heart disease requiring single valve replacement in our center from February 2019 to march 2020. Simple randomization technique was used for dividing into two groups of 50 patients each and were given del-nido or st Thomas II cardioplegia accordingly. Perioperative TROPONIN levels, TEE ejection fraction, post-operative inotrope requirement was analyzed. Results: Total of 100 Patients were enrolled in the studie. Mean troponin T immediate post CPB was 559.76 in del nido and 531.14 in blood showing no significance (P 0.146) and 24hrs post-surgery where 290.08 and 231.6 respectively with no significant (0.089) difference. Other parameters like coming of pump need for defibrillation(p-0.629), change in EF measured pre and post CPB (p-0.678) did not show any signifance. Conclusion: Myocardial protection in open cardiac surgery is still evolving. Del-nido cardioplegia is a viable alternative to st thomas cardioplegia which has proven to be statically equivalent in myocardial protection in adult population also. Further studies are required to look into the long-term outcome of use of del nido and to expand the use of del-nido cardioplegia in other adult open cardiac surgeries.
\end{abstract}

\section{Hosted file}

Journal of cardiac surgery manuscript.pdf available at https://authorea.com/users/438608/ articles/539764-del-nido-vs-st-thomas-ii-cardioplegia-in-adult-cardiac-surgery-aprospective-randomized-trial-of-short-term-outcomes

\section{Hosted file}

tables and charts.docx available at https://authorea.com/users/438608/articles/539764-delnido-vs-st-thomas-ii-cardioplegia-in-adult-cardiac-surgery-a-prospective-randomizedtrial-of-short-term-outcomes 